\title{
Iterative Deconvolution of PEA Measurements for Enhancing the Spatial Resolution of Charge Profile in Space Polymers
}

\author{
Mohamad Arnaout, ${ }^{1}$ Khaled Chahine, ${ }^{1}$ Fulbert Baudoin, ${ }^{2}$ \\ Laurent Berquez, ${ }^{2}$ and Denis Payan ${ }^{3}$ \\ ${ }^{1}$ Department of Electrical and Electronics Engineering, Lebanese International University, Mazraa, 146404 Beirut, Lebanon \\ ${ }^{2}$ LAPLACE, University of Toulouse, UPS, INPT 118 route de Narbonne, 31062 Toulouse Cedex 9, France \\ ${ }^{3}$ CNES, 18 avenue Edouard Belin, 31401 Toulouse Cedex 9, France \\ Correspondence should be addressed to Khaled Chahine; khaled.chahine@liu.edu.lb
}

Received 11 March 2016; Accepted 6 June 2016

Academic Editor: Alan K. T. Lau

Copyright (c) 2016 Mohamad Arnaout et al. This is an open access article distributed under the Creative Commons Attribution License, which permits unrestricted use, distribution, and reproduction in any medium, provided the original work is properly cited.

This work aims to improve the PEA calibration technique through defining a well-conditioned transfer matrix. To this end, a numerical electroacoustic model that allows determining the output voltage of the piezoelectric sensor and the acoustic pressure is developed with the software COMSOL ${ }^{\bullet}$. The proposed method recovers the charge distribution within the sample using an iterative deconvolution method that uses the transfer matrix obtained with the new calibration technique. The obtained results on theoretical and experimental signals show an improvement in the spatial resolution compared with the standard method usually used.

\section{Introduction}

In space applications, dielectrics placed on satellites can become electrically charged under the effect of bombardment with charged particles or ionizing radiation. This dielectric charging can reach a level of voltage capable of initiating a fast discharging process referred to as electrostatic surface discharge, which causes harmful interference with electronic components $[1,2]$. To better control the discharging process, it becomes imperative to determine the kind, distribution, and amount of bulk charges with time and to understand the charge carrier in dielectrics used in satellites. The pulsed electroacoustic method (PEA) has been used to this end [39]. This technique, however, is known to be limited to about $10 \mu \mathrm{m}$ in spatial resolution. Given the fact that the dielectric thickness used in spacecraft structure can be about $50 \mu \mathrm{m}$, such a resolution is not adequate. Therefore, enhancing PEA resolution is necessary to ensure accurate information about charge carrier.

In [10], the charge distribution in dielectric material was estimated using a reference signal determined from a DC constraint on a blank sample. The reference signal serves to determine the transfer function of the piezoelectric sensor. This method, however, results in an ill-conditioned transfer matrix that negatively affects the resolution of charge distribution. In [11], a full PEA model was developed with the aim of optimizing the cell design. The model is capable of predicting the voltage signal of the piezoelectric sensor for any charge profile in the sample. Based on this full model, this paper proposes a new iterative deconvolution method that results in a well-conditioned transfer matrix of the entire cell. The proposed method is tested on simulated and experimental signals. Results show a good correlation between the simulated and the real charges. In addition an improvement in resolution is achieved compared with the conventional method.

The rest of the paper is organized as follows: Section 2 briefly recalls the PEA measurement principle and presents an electroacoustic model for the PEA cell, Section 3 recalls the calibration method of [10] and details the proposed calibration method, Section 4 studies the performance of the 


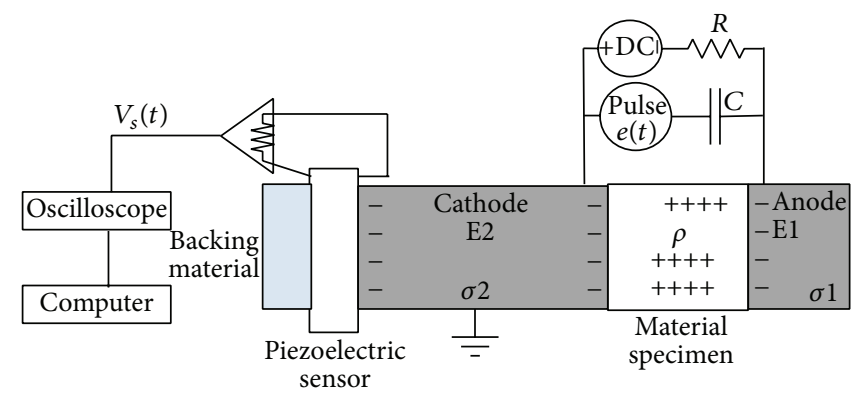

FIGURE 1: PEA measurement principle.

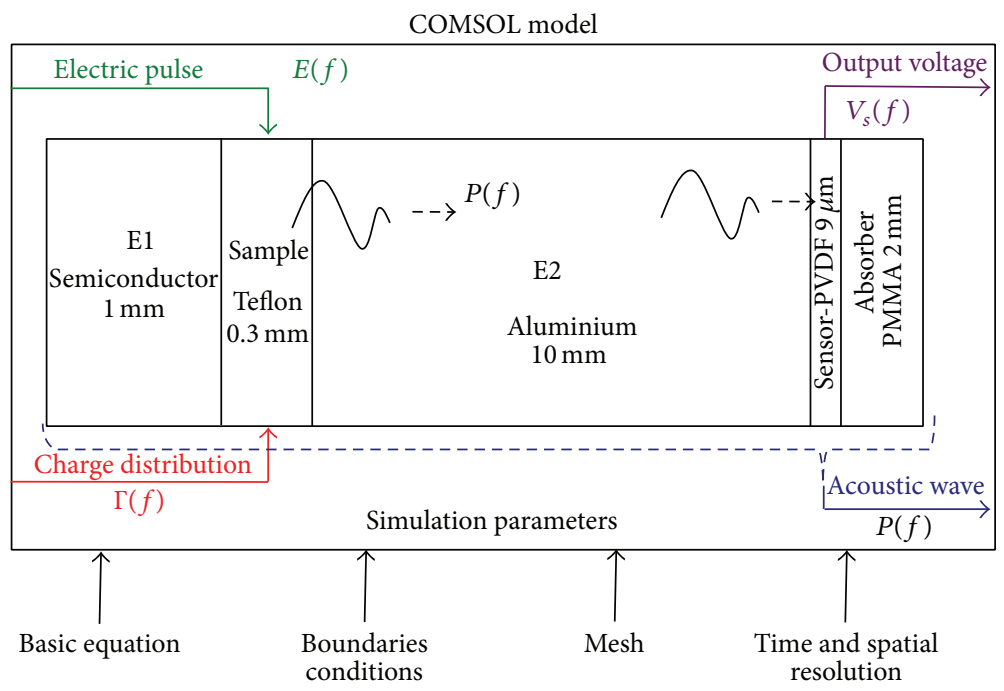

Figure 2: The COMSOL model of PEA cell [11].

two methods on simulated and experimental data, and finally Section 5 provides the summary and conclusion.

\section{Pulsed Electroacoustic Cell}

2.1. PEA Measurement Principle. Figure 1 shows the PEA measurement principle. An insulator is inserted between the two electrodes E1 and E2 and an SC-film is placed between E2 and the sample to ensure better acoustic impedance. An electric impulse $e(t)$ on $\mathrm{E} 1$ is applied to excite charges within the sample.

As a result of this excitation, an acoustic wave $p(t)$ is produced in the sample and propagates through E2. The acoustic transducer converts this wave into an electric signal $V_{s}(t)$. This signal is amplified by a $30 \mathrm{~dB}$ amplifier and then processed to explore the charge profile.

2.2. Electroacoustic Model. Acoustic wave propagation is simulated using $\mathrm{COMSOL}^{\oplus}$ [12]. The numerical model of the PEA cell is divided into five domains: E1, sample, E2, PVDF, and the absorber (Figure 2). This model is able to simulate the acoustic wave propagation for any charge distribution.
Figure 3 shows a charge density profile and its corresponding output voltage signal, usually referred to as the calibration signal, when a noncharged sample is considered. This simulated voltage signal will be used to analyze and compare the charge profile estimated using the calibration method proposed by Maeno et al. in [10], denoted as Method 1, with the charge profile estimated by the iterative deconvolution method proposed in this work, denoted as Method 2.

\section{Signal Processing}

3.1. Aim of PEA Signal Processing. PEA signal processing is one of the important steps for estimating space charge in sample. The purpose of PEA system is to determine charge profile $\rho_{\text {calibration }}$ given in (1), knowing the output voltage $V_{s}(t)$ and adjusting the PEA transfer function $H_{\mathrm{PEA}}$ :

$$
V_{s}=H_{\mathrm{PEA}} \cdot \rho_{\text {calibration }} \cdot
$$

Determining $H_{\mathrm{PEA}}$ passes through an initial procedure known as calibration. In the following, we explain this approach for Method 1 and Method 2. 


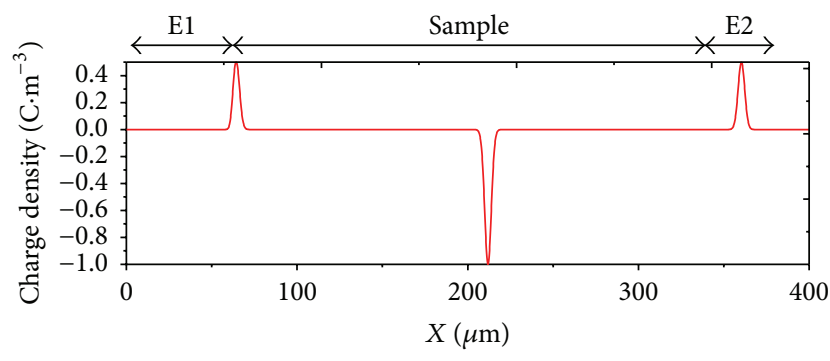

(a)

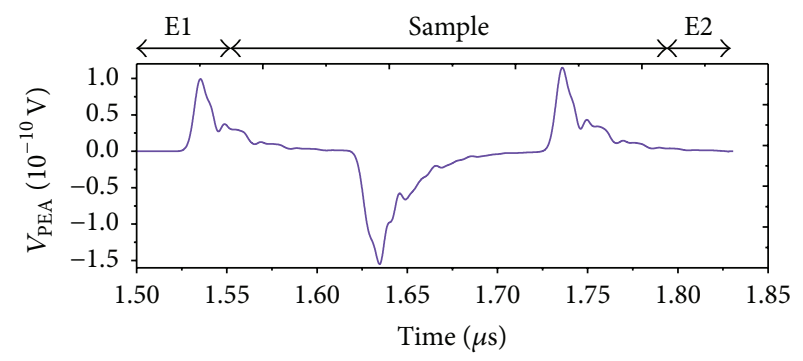

(b)

Figure 3: (a) The net charge density for a charged sample using normalized value. (b) Sensor output voltage.
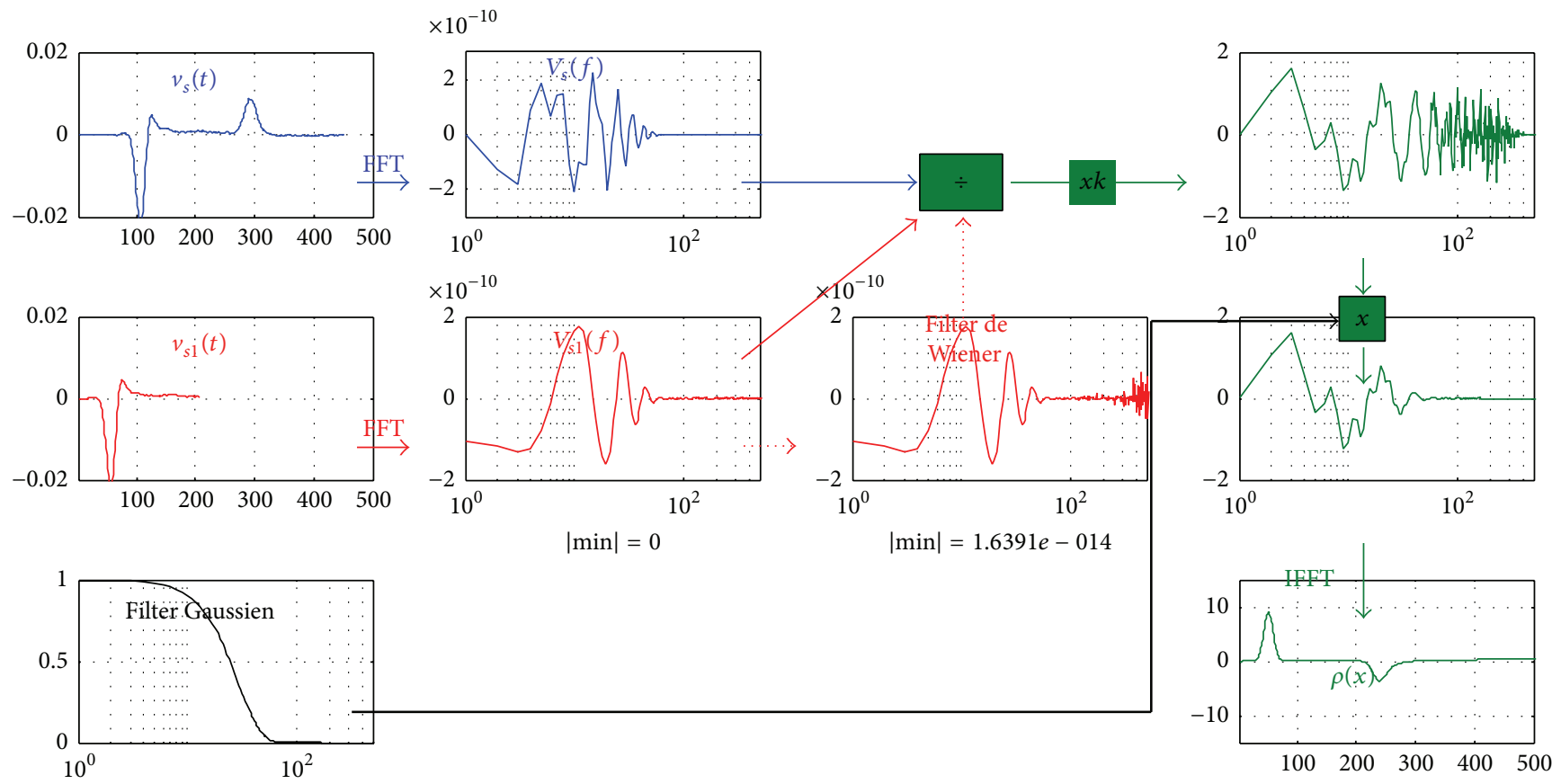

FIGURE 4: Flow chart of the signal processing based on Method 1.

3.2. Signal Processing Used by Method 1. The signal processing used by Method 1 relies on the convolution product between charge profile and the electric pulse. In the frequency domain, we have

$$
\begin{gathered}
P(f)=K \cdot v_{\text {sample }} \cdot R(f) \cdot E(f) \\
\cdot \exp \left(-i 2 \pi f \cdot \frac{l}{v_{A l}}\right),
\end{gathered}
$$

where $K$ is a constant, $v_{\text {sample }}$ and $v_{A l}$ are, respectively, the sound velocities in the sample and E2, and $l$ is the thickness of electrode E2. $R(f), E(f)$, and $P(f)$ are, respectively, the Fourier transform of charge density $\rho(t)$, electric pulse $e(t)$, and pressure wave $p(t)$. As shown in Figure 2, the transfer function of the piezoelectric transducer is the only unknown:

$$
V_{s}(f)=H_{\text {sensor }}(f) P(f) .
$$

This function $\left(H_{\text {sensor }}\right)$ is determined assuming a Dirac distribution of electric charge at $\mathrm{E} 1$ and E2. Then, $R(f)=1$ and (2) becomes

$$
\begin{aligned}
P_{\text {calibration }}(f) & =A \cdot E(f) \cdot \exp \left(-i 2 \pi f \cdot \frac{l}{v_{A l}}\right), \\
V_{\text {calibration }} & =P_{\text {calibration }} \cdot H_{\text {sensor }},
\end{aligned}
$$

where $A$ is a constant determined from the total electric charge $Q$ in sample. Using (1)-(4), the charge profile could be calculated as follows:

$$
R(f)=\frac{A \cdot V_{s}(f)}{K \cdot v_{\text {sample }} \cdot V_{\text {calibration }}(f)} .
$$

$H_{\text {PEA }}$ can be expressed theoretically as

$$
H_{\mathrm{PEA}}=\frac{K \cdot v_{\text {sample }} \cdot V_{\text {calibration }}(f)}{A} .
$$



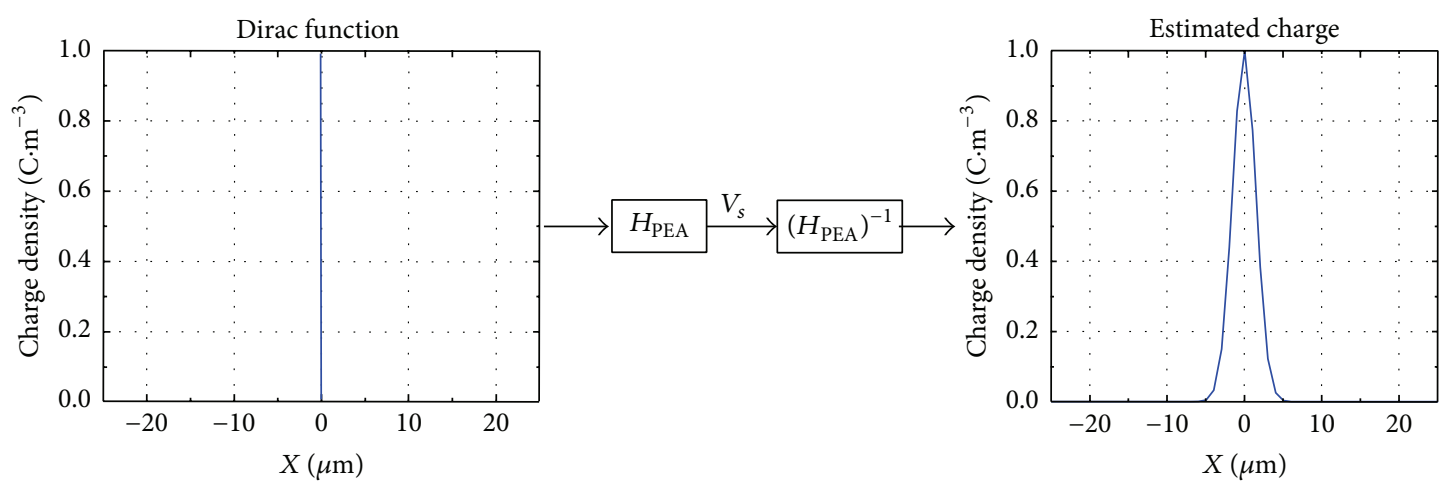

FIGURE 5: Estimated charge profile by Method 1.

Obtaining the charge distribution $\rho(x)$ experimentally requires dividing $V_{s}(f)$ by $V_{\text {calibration }}(f)$ and determining the inverse Fourier transform of $R(f)$. As shown in Figure 4, this is achieved by a deconvolution technique that uses two functions: a Gauss function to limit the frequency range of the signal spectrum filter and a Wiener function to avoid the division by zero in the Fourier domain $[13,14]$. The inconvenience of using Gauss filter has to manually set a parameter $R$ that is directly linked to the bandwidth. A low bandwidth provides high value of $R$, whereas a low value of this parameter involves a higher cut-off frequency (the effect of $R$ is discussed later).

Accounting for the practical considerations of this implementation, the expression of $H_{\mathrm{PEA}}$ is then written as

$$
H_{\text {PEA }}=\frac{K \cdot v_{\text {sample }} \cdot V_{\text {calibration }}(f) \cdot H_{\text {Wiener }}(f)}{A \cdot H_{\text {Gauss }}(f)} .
$$

Finally, the charge profile of the sample can be determined after defining the Wiener function, the Gauss filter whose parameter $R$ is set manually, and the constant $A$ which is related to the surface charge $Q$. Figure 5 shows the normalized estimated charge profile on one electrode calculated by Method 1, which consists of Gaussian-shaped pulse instead of the Dirac pulse of the true profile. Therefore Method $1 \mathrm{did}$ not respect the initial assumption.

3.3. Calibration Method and Signal Processing of Method 2. In [11], it was found that using Dirac distribution that leads to determine the PEA transfer matrix did not guarantee a well-conditioned system that affords the same shape and amplitude of electric charge in a sample. To enhance the condition number of the PEA transfer matrix, we propose to adopt the Gaussian distribution for the electric charge. Hence, the electric charge density on both electrodes is assimilated to a Gaussian shape centred on the corresponding electrode, as depicted in Figure 6. The charge distribution is then given by

$$
\rho_{\text {calibration }}=A_{\text {cal }} \cdot e^{-2\left(x-x_{0}\right)^{2} / d^{2}},
$$

where $x_{0}$ is the position of electric charge and $A_{\text {cal }}$ and $d$ are the amplitude and spreading of the electric charge profile, respectively.

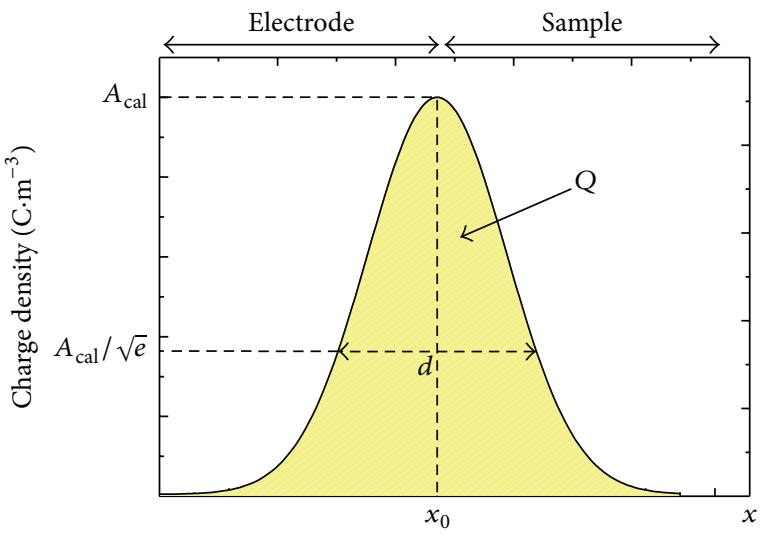

FIGURE 6: Electric charge profile used in calibration method.

In addition, the net electric charge density $Q$ on both electrodes is considered to be equal to the capacitive charge $Q=C_{s} U$, where $C_{s}$ is the sample surface capacitance and $U$ is the applied voltage. $A_{\text {cal }}$ is related to the electric charge $Q$ and to the charge spreading $\mathrm{d}$ by the following relation:

$$
Q=C_{s} U=\int_{-\infty}^{+\infty} A_{\mathrm{cal}} e^{-2\left(x-x_{0}\right)^{2} / d^{2}} d x=\frac{A_{\mathrm{cal}} d}{\sqrt{\pi / 2}} .
$$

It can be seen that once $d$ is known, $\rho_{\text {calibration }}$ can be determined.

3.4. Characterization of the PEA Transfer Matrix Based on the Gaussian Distribution-Method 2. Calibration is an essential stage for an accurate determination of the electric charge distribution using PEA method $[10,15,16]$. The goal of the new calibration method is to determine the PEA transfer matrix. The proposed method starts by relating $V_{\text {calibration }}$ which is the response of the capacitive charge $\rho_{\text {calibration }}$ on the electrodes, to $\rho_{\text {calibration }}$ by Toeplitz matrix $H_{\mathrm{PEA}}$ constructed from the impulse response $H_{\mathrm{PEA}}(t)$ of the PEA cell [17]:

$$
V_{\text {calibration }}=H_{\text {PEA }} \rho_{\text {calibration }}
$$


with

$$
\begin{aligned}
& H_{\mathrm{PEA}}=\left[\begin{array}{cccccccc}
h_{1} & 0 & \cdots & \cdots & 0 & h_{n_{h}} & \cdots & h_{2} \\
h_{2} & h_{1} & 0 & \cdots & \cdots & 0 & h_{n_{h}} & \cdots \\
\vdots & h_{2} & h_{1} & 0 & \cdots & \cdots & 0 & h_{n_{h}} \\
h_{n_{h}} & \vdots & h_{2} & h_{1} & 0 & \cdots & \cdots & 0 \\
0 & h_{n_{h}} & \vdots & h_{2} & h_{1} & 0 & \cdots & \cdots \\
\vdots & 0 & h_{n_{h}} & \vdots & h_{2} & h_{1} & 0 & \cdots \\
\vdots & \vdots & 0 & h_{n_{h}} & \vdots & h_{2} & h_{1} & 0 \\
0 & \vdots & \vdots & 0 & h_{n_{h}} & \vdots & h_{2} & h_{1}
\end{array}\right] \text {, } \\
& \rho_{\text {calibration }}=\left(\begin{array}{c}
\rho_{0} \\
\rho_{1} \\
\vdots \\
\rho_{n_{c}-1} \\
\rho_{n_{c}} \\
0 \\
\vdots \\
0
\end{array}\right) \text {, } \\
& V_{\text {calibration }}=\left(\begin{array}{c}
v_{0} \\
v_{1} \\
\vdots \\
v_{N-1} \\
v_{N}
\end{array}\right) \text {, }
\end{aligned}
$$

where $n_{h}, n_{c}$, and $N=n_{h}+n_{c}-1$ are the numbers of samples of $H_{\mathrm{PEA}}(t), \rho_{\text {calibration }}$, and $V_{\text {calibration }}$, respectively.

Equation (10) can be rewritten as

$$
V_{\text {calibration }}=H_{\rho} \cdot H_{\mathrm{PEA}}
$$

with

$$
H_{\mathrm{PEA}}=\left(\begin{array}{c}
h_{1} \\
h_{2} \\
\vdots \\
h_{n_{h}} \\
0 \\
\vdots \\
\vdots \\
0
\end{array}\right)
$$

$$
H_{\rho}=\left[\begin{array}{cccccccc}
\rho_{1} & 0 & \cdots & \cdots & 0 & \rho_{n_{c}} & \cdots & \rho_{2} \\
\rho_{2} & \rho_{1} & 0 & \cdots & \cdots & 0 & \rho_{n_{c}} & \cdots \\
\vdots & \rho_{2} & \rho_{1} & 0 & \cdots & \cdots & 0 & \rho_{n_{c}} \\
\rho_{n_{c}} & \vdots & \rho_{2} & \rho_{1} & 0 & \cdots & \cdots & 0 \\
0 & \rho_{n_{c}} & \vdots & \rho_{2} & \rho_{1} & 0 & \cdots & \cdots \\
\vdots & 0 & \rho_{n_{c}} & \vdots & \rho_{2} & \rho_{1} & 0 & \cdots \\
\vdots & \vdots & 0 & \rho_{n_{c}} & \vdots & \rho_{2} & \rho_{1} & 0 \\
0 & \vdots & \vdots & 0 & \rho_{n_{c}} & \vdots & \rho_{2} & \rho_{1}
\end{array}\right] .
$$

As shown in (12), $H_{\rho}$ is a Toeplitz matrix constructed from the samples of the charge distribution used in calibration. Knowing $V_{\text {calibration }}$, the impulse response of the system $H_{\text {PEA }}$ can be determined (Figure 7).

In fact, a procedure of four steps is followed to determine the transfer matrix.

S1. Initialize the Gaussian shape at the Electrode/Sample interface by assigning to $d$ the value of the thickness of the sensor (in order to accommodate the entire incoming signal) and then we deduce $A_{\text {cal }}$ using (9).

S2. Construct a Toeplitz $H_{\rho}$ matrix from electric capacitive charge $\rho_{\text {calibration }}$ according to (13).

S3. Determine the system impulse response. Once $H_{\rho}$ is obtained and considering calibration signal $V_{\text {calibration }}$, the cell impulse response $H_{\mathrm{PEA}}$ is calculated as follows:

$$
H_{\mathrm{PEA}}=H_{\rho}^{-1} \cdot V_{\text {calibration }} \text {. }
$$

S4. Assess the PEA transfer matrix through

$$
\rho=H_{\mathrm{PEA}}^{-1} \cdot V_{s} .
$$

An enhanced result is achieved by using the following iterative procedure.

S1. Initialize a spreading $d_{h}$ equal to the sensor thickness.

S2. Calculate the transfer matrix $H_{\text {PEA }}$.

S3. Deconvolve the reference signal to obtain $\rho_{\text {calibration }}$.

S4. Determine the calibration spreading $d_{c}$ at the electrodes.

S5. Repeat step 1 with $d_{h}=d_{c}$ until $d_{h}-d_{c}=0$.

This approach is illustrated in the flowchart shown in Figure 8. Using Method 2, the charge profile is obtained after the adjustment of only one parameter, which is the surface charge $Q$ [18]. 


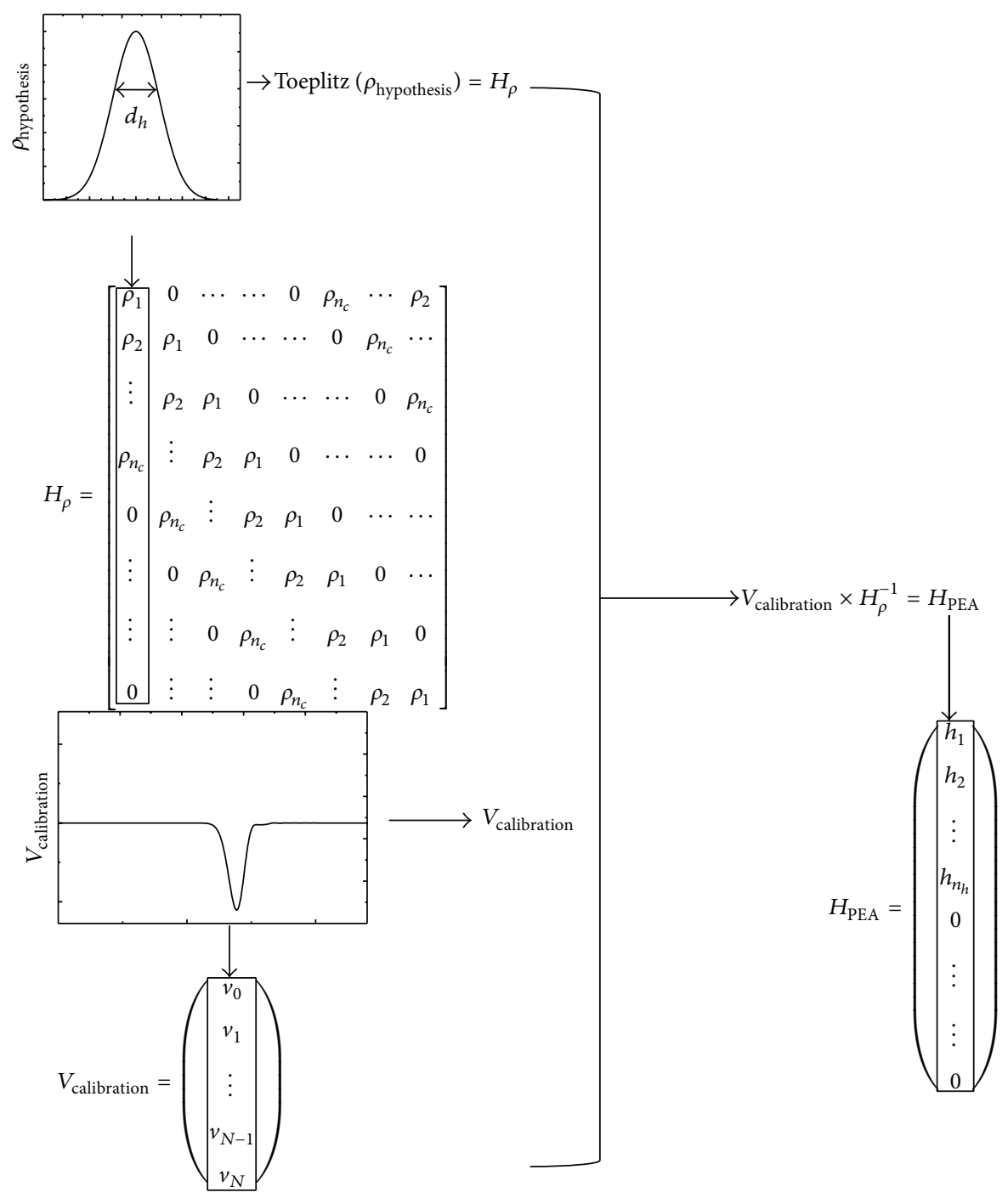

FIgURE 7: Estimation of $H_{\text {PEA }}$.

The utility of this method in obtaining accurate shape and amplitude of the normalized imposed charge profile on one electrode can be seen in Figure 9.

Unlike Method 1, Method 2 allows recovering the initial assumption.

\section{Results}

4.1. Simulated Data. This part is based on a comparison between Method 1 and Method 2 with respect to the spatial resolution of the charge profile. To do that, a charge distribution in a $300 \mu \mathrm{m}$ sample is considered as input for the electroacoustic model. As shown in Figure 10, this charge distribution possesses two negative peaks distant by $5 \mu \mathrm{m}$ in the middle of the sample along with image charges at the electrodes. Feeding this distribution to the model yields the output voltage $V_{s}(t)$ also shown in Figure 10 .

Based on the output signal and after finalizing the calibration steps, charge distributions are determined using Method 1 and Method 2. They are given in Figures 11 and 12, respectively. Method 1 requires defining the parameter $R$. Two different values of $R$ were tested: $R=5$ and $R=8$. For $R=5$ the shape of the charge distribution is completely different from the original shape due the presence of oscillations. The reason is that the cut-off frequency is not adequate to remove all the noise. For $R=8$, the noise is almost completely suppressed. However, a part of useful signal is eliminated due to the value of the cut-off frequency of the low pass-filter. Indeed, in this case, the two peaks cannot be discerned. This example clarifies the trade-off between high signal quality and resolution.

Figure 12 shows estimated charge using Method 2. It can be seen that the charge estimated is very close to the original shape. Some disturbances appear around each peak. This effect is due to the high condition number of the overall transfer function which is higher than 1 .

4.2. Experimental Data. This study is carried out for two different samples: a PTFE sample of $300 \mu \mathrm{m}$ thickness and 


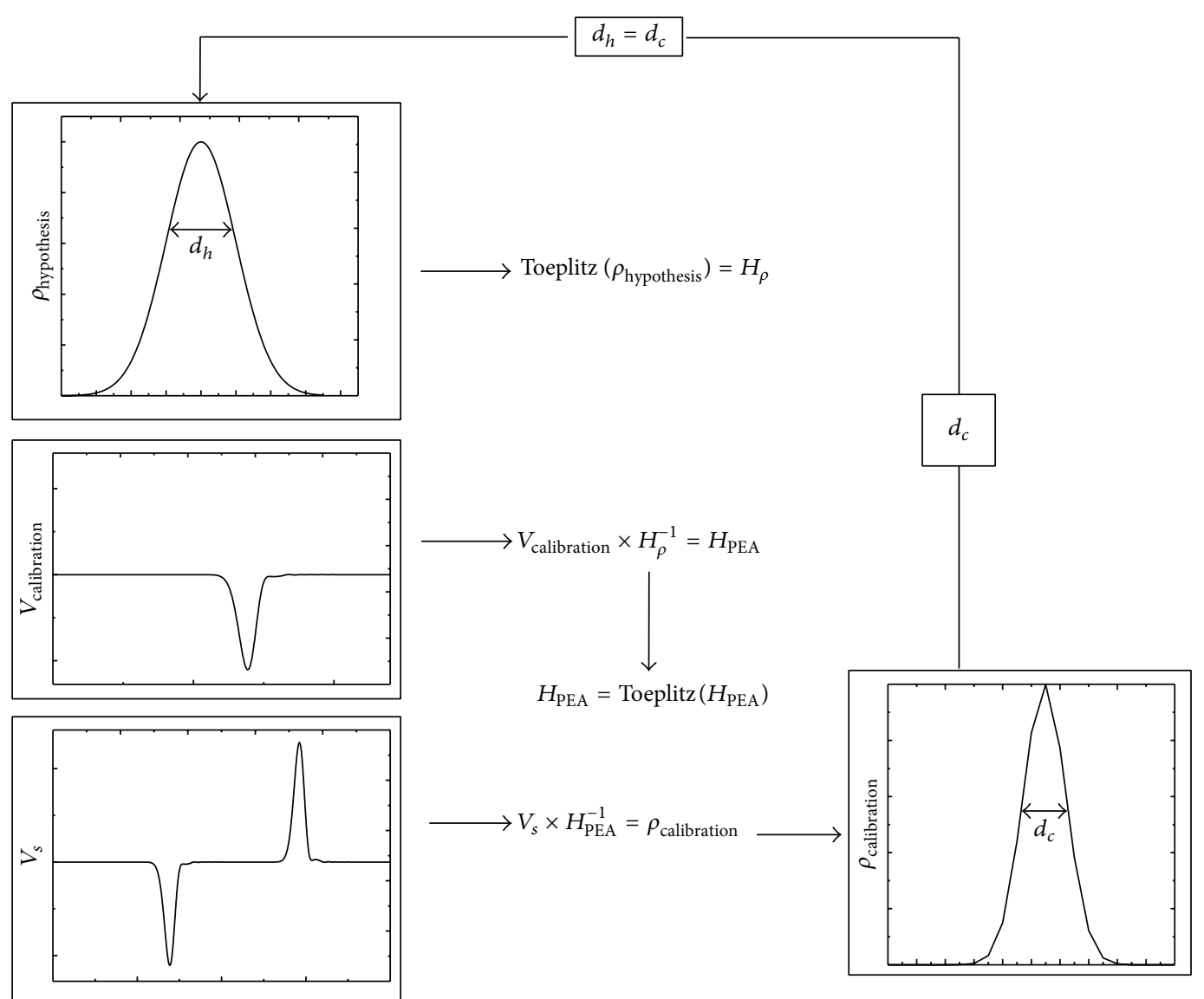

FIGURE 8: Flowchart of the signal processing implementation of Method 2.
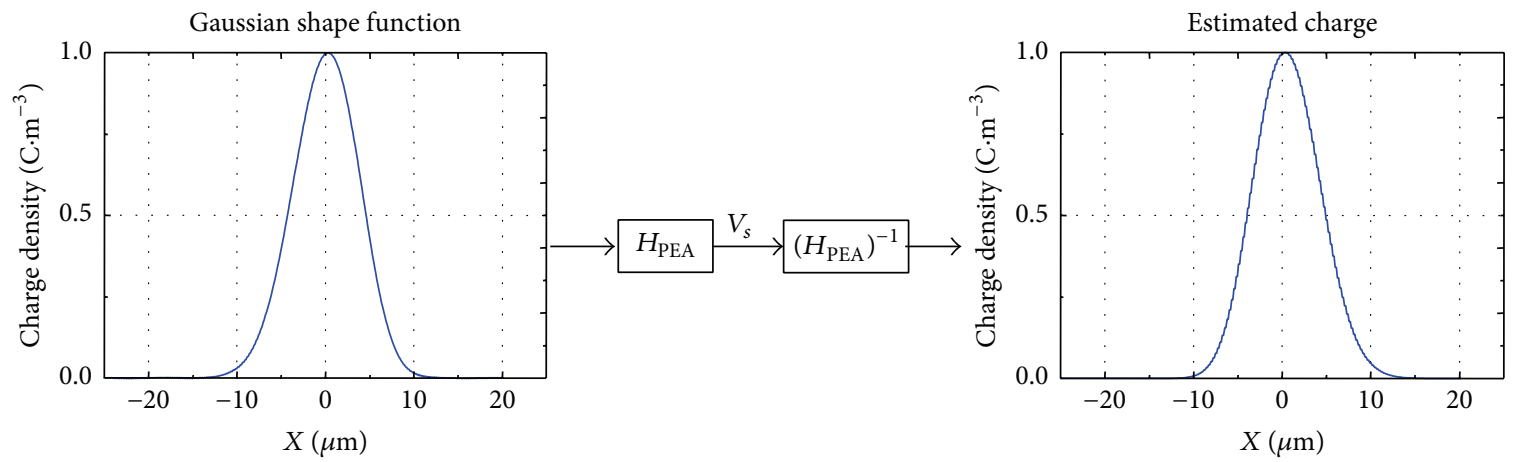

FIGURE 9: Estimated charge profile by Method 2.

an FEP sample of $250 \mu \mathrm{m}$ thickness. It consists of calibration followed by estimation of charge profile after irradiation.

4.3. Calibration. The calibrated profile is obtained from a PEA measurement of a polarized blank PTFE sample. Polarization is done after $10 \mathrm{~s}$ under $3 \mathrm{kV}$. Figure 13 shows the acquisition system and the PEA cell device. The PEA cell is placed in an enclosure to eliminate interference induced by the local environment.
Figure 14 shows the charge density estimated by Method 1 and Method 2 during calibration. The value of parameter $R$ is set to 10 since this value eliminates oscillations and provides a proper signal. In this step of measurement, we can notice a difference between the two charges profiles.

From Figure 14(a), it can be seen that Method 1 results in a resolution of $9 \mu \mathrm{m}$ and a maximum value of $18 \mathrm{C} \cdot \mathrm{m}^{-3}$, whereas Method 2 results have a spatial resolution of $6 \mu \mathrm{m}$ with a maximum value of $24 \mathrm{C} \cdot \mathrm{m}^{-3}$. Moreover, the Bode 

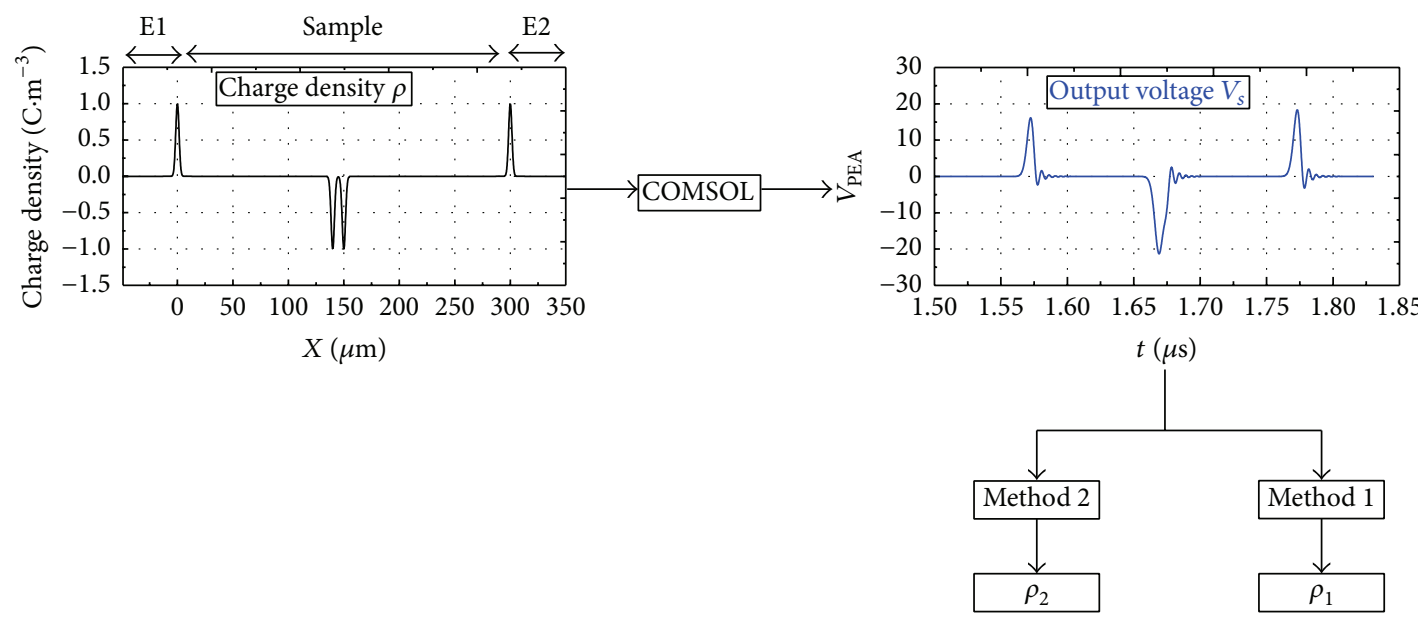

FIGURE 10: Simulated charge density and output voltage.

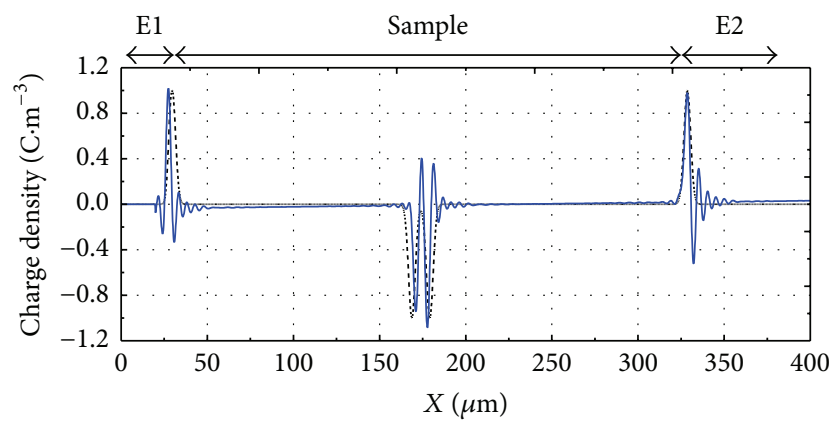

- Estimated charge with $R=5$

_ Charge within the bulk

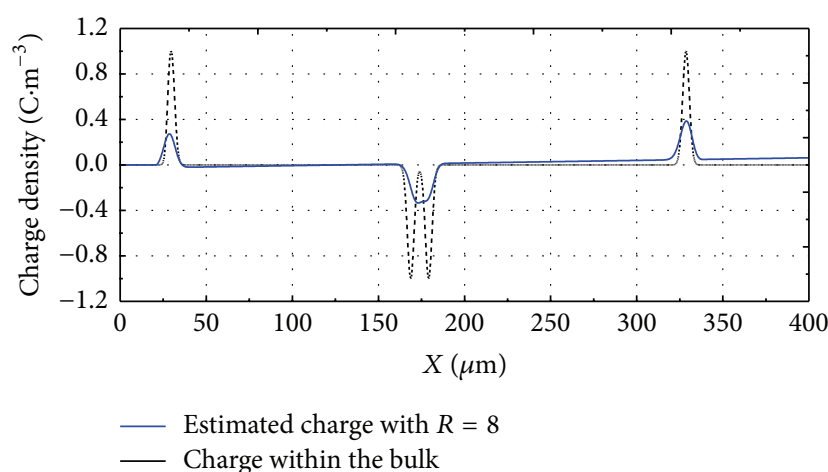

Figure 11: Estimated charge distribution by Method 1.

diagram of the output PEA signal in Figure 14(b) shows that the bandwidth is largest when Method 2 is used, thus affording a better resolution of the charge distribution within the sample. Indeed, the bandwidth defined at $-3 \mathrm{~dB}$ is about $19 \mathrm{MHz}$ for Method 1 and $69 \mathrm{MHz}$ for Method 2.

\subsection{Estimation of the Charge Profile after Irradiation. A PTFE} sample was irradiated at $30 \mathrm{keV}$ during 20 minutes using SEM. Figure 15 presents a comparison of charge profiles after irradiation obtained using Method 1 and Method 2. An

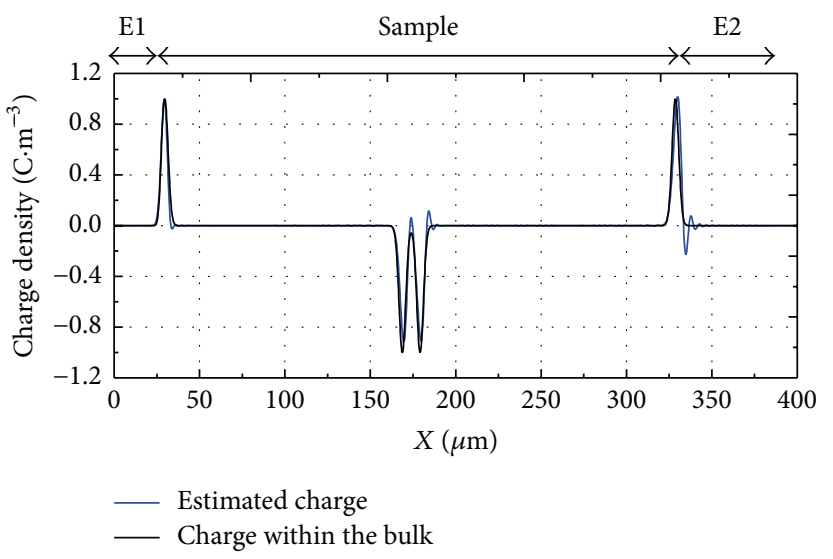

FIgURE 12: Estimated charge distribution by Method 2.

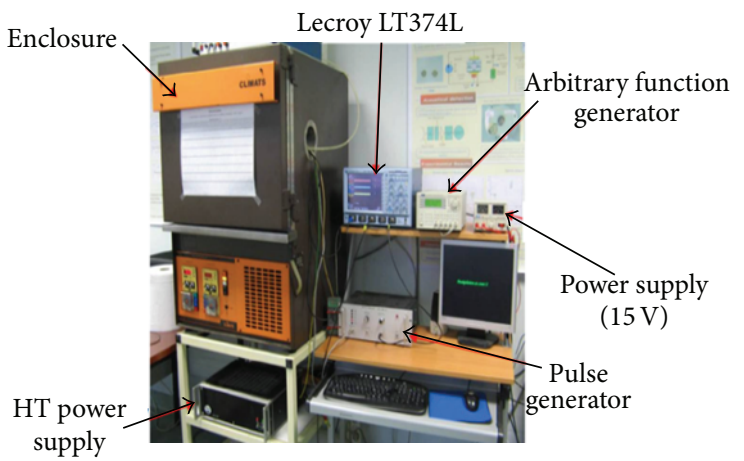

FIGURE 13: Acquisition system (to the left) and PEA cell device (to the right).

improvement of the spatial resolution is observed, as the full width at half maximum is $6 \mu \mathrm{m}$ for Method 2 versus $9 \mu \mathrm{m}$ for Method 1. Another remark from Figure 15 is that a lower penetration of charge in the bulk occurs when Method 2 is used; a maximum value of $6.8 \mu \mathrm{m}$ compared with $9.1 \mu \mathrm{m}$ for Method 1. 


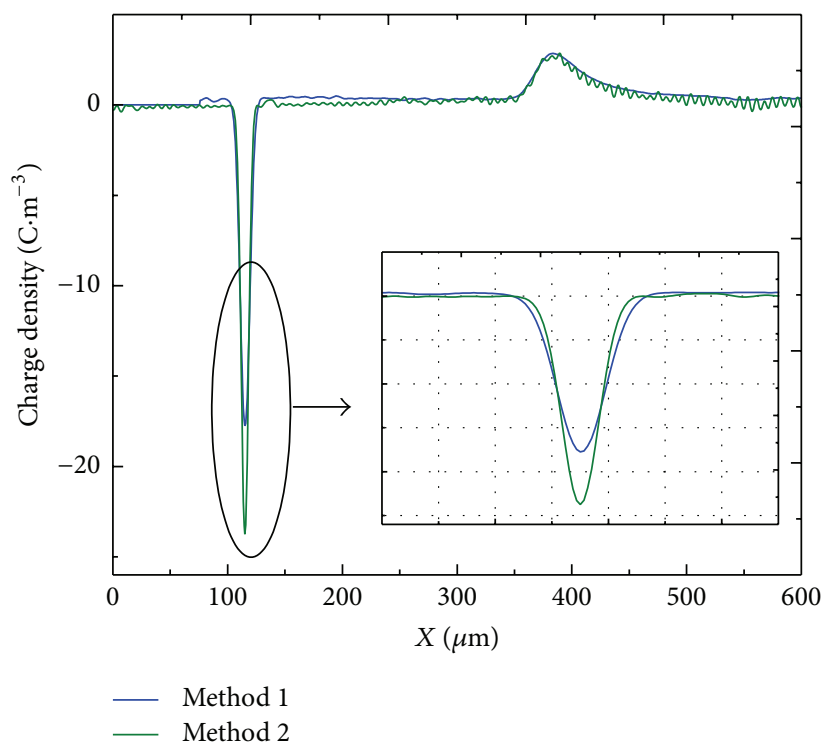

(a)

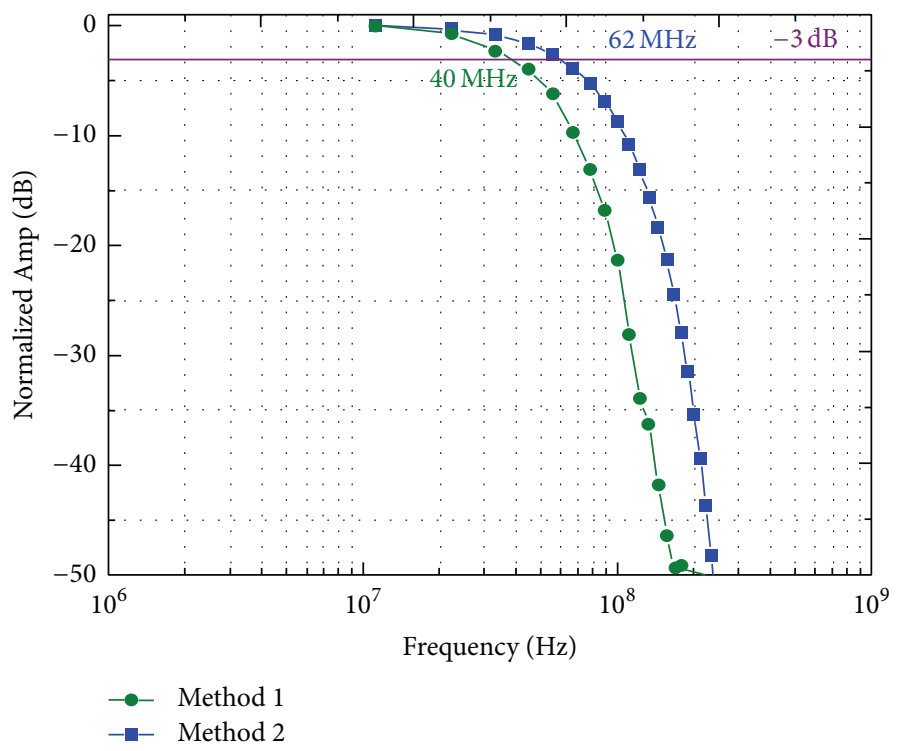

(b)

FIGURE 14: (a) Calibrated charge distribution. (b) Bode diagram calculated by Method 1 and Method 2 for PTFE.

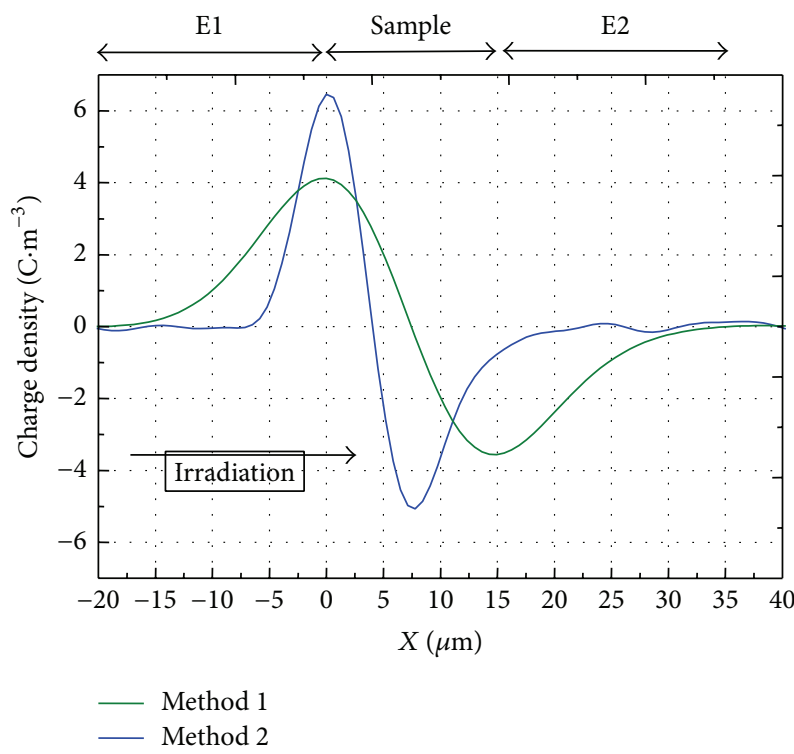

FIGURE 15: Charge profile calculated by Method 1 and Method 2 for PTFE after irradiation.

These methods were also tested on a $250 \mu \mathrm{m}$ thick FEP sample. The dedicated irradiation chamber SIRENE [19-21] and a special PEA cell without contact Figure 16 were used in order to determine the charge profile. The same flux of electrons, of about $100 \mathrm{pA} \cdot \mathrm{cm}^{-2}$, was used for two energy levels at $20 \mathrm{keV}$ and $145 \mathrm{keV}$.

The result of Method 1 was obtained for $R=10$, whereas those of Method 2 were calculated automatically. The $20 \mathrm{keV}$ aims to implement electrons close to the irradiated surface. For the $145 \mathrm{keV}$, however, charges are injected approximately

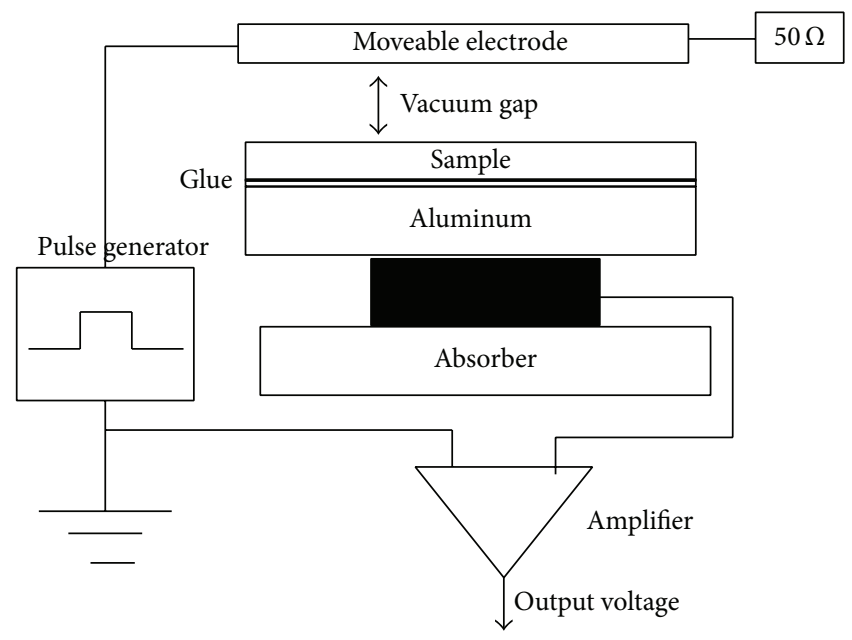

FIGURE 16: Schematic of PEA without contact cell device adopted in SIRENNE.

at the middle of the samples. This phenomenon was observed for both methods, but the advantage of Method 2 resides in the automatic calculation of the charge profile within the samples. Moreover, an enhancement of charge resolution has been obtained (Figure 17(a)), mainly at the electrode-sample interface. In addition, the difference in percentage between the amplitude of charges density issued from the $20 \mathrm{keV}$ between Method 2 and Method 1 is about 13\%. However, for the $145 \mathrm{keV}$, this difference is $50 \%$.

Figure 17(b) shows the profile of charge density issued from the $145 \mathrm{keV}$. The full width at half maximum (FWHM) and the total electric charges can be estimated. Method 1 gives a resolution of $\mathrm{FWHM}=10.6 \mu \mathrm{m}$ and a maximum charge 


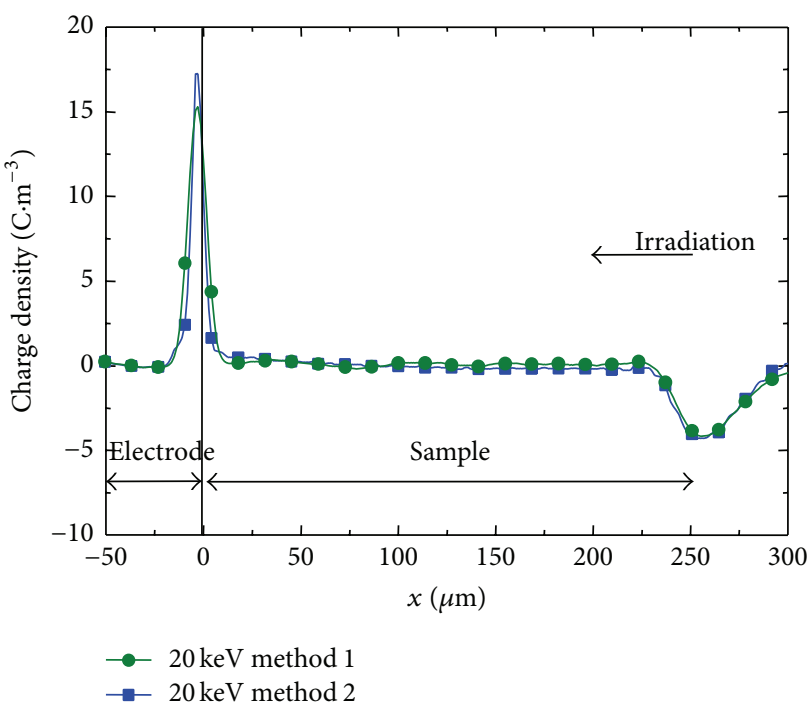

(a)

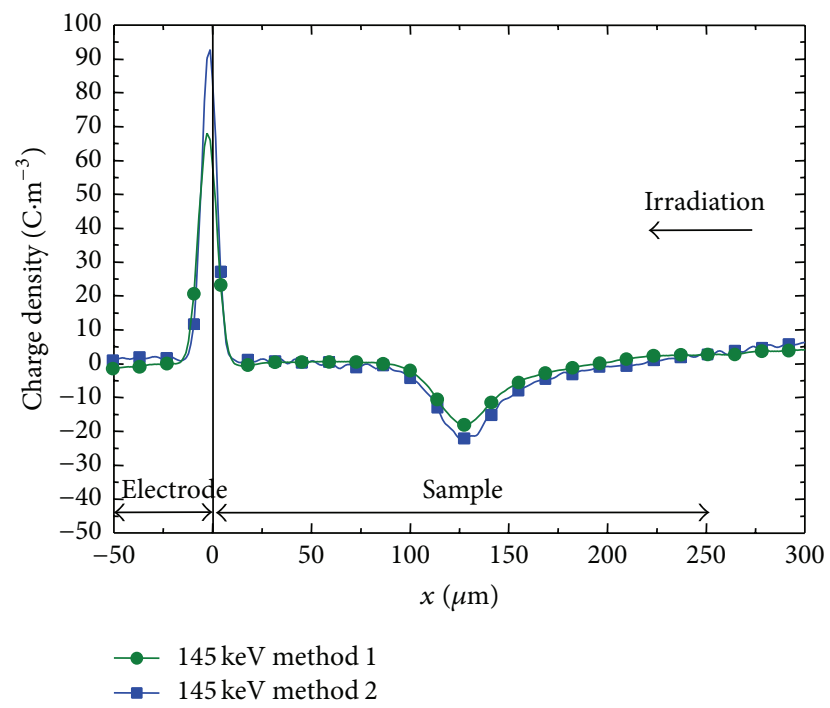

(b)

FIGURE 17: Charges profiles issued from FEP sample after irradiation using Method 1 and Method 2. (a) With an energy of $20 \mathrm{keV}$. (b) With an energy of $145 \mathrm{keV}$.

of $68 \mathrm{C} \cdot \mathrm{m}^{-3}$, while with Method 2 the spatial resolution is $\mathrm{FWHM}=9.4 \mu \mathrm{m}$ and with a maximum charge of $92 \mathrm{C} \cdot \mathrm{m}^{-3}$.

\section{Conclusion}

This paper presented a new calibration method based on an iterative deconvolution scheme that aims to determine the PEA transfer function. The iterative nature of the proposed method allows overcoming the ill conditioning of the transfer matrix and thus improving the quantitative interpretation of the results. For both simulated and experimental data, results obtained by the proposed method showed improvement in the spatial resolution of the charge density profile and oscillation suppression, when compared with those of a method used in the literature. Also, in contrast to the calibration methods usually used where a resolution parameter must be defined without any physical criterion (only visual quality of the result allows defining this parameter), the proposed method yields a well-conditioned transfer matrix without human intervention.

\section{Competing Interests}

The authors declare that they have no competing interests.

\section{References}

[1] H. C. Koons, J. E. Mazur, R. S. Selesnick et al., "The impact of the space environment on space systems," in Proceedings of the 6th Spacecraft Charging Technology Conference, pp. 7-11, Air Force Research Laboratory Science Center, Air Force Base, Mass, USA, 2000.

[2] K. G. Balmain, "Space experiment design for electrostatic charging and discharging," in Proceedings of the 9th CASI Conference on Astronautics, pp. 115-122, Ottawa, Canada, November 1996.
[3] T. Takada, T. Maeno, and H. Kushibe, "An electric stress-pulse technique for the measurement of charges in a plastic plate irradiated by an electron beam," IEEE Transactions on Electrical Insulation, vol. EI-22, no. 4, pp. 497-501, 1987.

[4] M. Fukuma, T. Maeno, and K. Fukunaga, "High repetition rate two-dimensional space charge measurement system," in Proceedings of the International Symposium on Electrical Insulating Materials (ISEIM '05), pp. 584-587, Kitakyushu, Japan, June 2005.

[5] V. Griseri, K. Fukunaga, T. Maeno, C. Laurent, L. Lévy, and D. Payan, "Pulsed electro-acoustic technique applied to in-situ measurement of charge distribution in electron-irradiated polymers," IEEE Transactions on Dielectrics and Electrical Insulation, vol. 11, no. 5, pp. 891-898, 2004.

[6] T. Maeno, "Three-dimensional PEA charge measurement system," IEEE Transactions on Dielectrics and Electrical Insulation, vol. 8, no. 5, pp. 845-848, 2001.

[7] T. Muronaka, Y. Tanaka, and T. Takada, "Measurement of space charge distribution in XLPE cable using PEA system with flat electrode," in Proceedings of the Annual Conference on Electrical Insulation and Dielectric Phenomena, pp. 266-269, Millbrae, Calif, USA, October 1996.

[8] C. Thomas, G. Teyssedre, and C. Laurent, "A new method for space charge measurements under periodic stress of arbitrary waveform by the pulsed electro-acoustic method," IEEE Transactions on Dielectrics and Electrical Insulation, vol. 15, no. 2, pp. 554-559, 2008.

[9] J. B. Bernstein, "Analysis of the electrically stimulated acousticwave method for observing space charge in semi-insulating films," Physical Review B, vol. 44, no. 19, pp. 10804-10814, 1991.

[10] T. Maeno, T. Futami, H. Kushibe, T. Takada, and C. M. Cooke, "Measurement of spatial charge distribution in thick dielectrics using the pulsed electroacoustic method," IEEE Transactions on Electrical Insulation, vol. 23, no. 3, pp. 433-439, 1988.

[11] M. Arnaout, F. Baudoin, L. Berquez, and D. Payan, "Study of signal treatment for a pulsed electro-acoustic measurement cell: a way of improving the transfer matrix condition number," 
Journal of Physics D: Applied Physics, vol. 44, no. 40, Article ID 405403, 2011.

[12] M. Arnaout, L. Berquez, F. Baudoin, and D. Payan, "Contribution to improving the spatial resolution of a pulsed electro acoustic cell measurement: an analysis of acoustics waves propagation," in Proceedings of the IEEE International Conference on Solid Dielectrics (ICSD '10), pp. 1-4, Potsdam, Germany, July 2010.

[13] Y. Sekii and T. Maeno, "Generation and dissipation of negative heterocharges in XLPE and EPR," IEEE Transactions on Dielectrics and Electrical Insulation, vol. 16, no. 3, pp. 668-675, 2009.

[14] K. Kaneko, T. Ozaki, E. Nakane, and T. Mizutani, "Space charge phenomena in polyimide films and effects of absorbed water," in Proceedings of the International Symposium on Electrical Insulating Materials (ISEIM '05), pp. 65-68, Kitakyushu, Japan, June 2005.

[15] O. G. Lavallee and G. Teyssedre, "Space charge measurement in solid dielectrics by the pulsed electro-acoustic technique," in Proceedings of the IEEE International Conference on Solid Dielectrics (ICSD '04), pp. 268-271, Toulouse, France, July 2004.

[16] G. Chen, Y. L. Chong, and M. Fu, "Calibration of the pulsed electroacoustic technique in the presence of trapped charge," Measurement Science and Technology, vol. 17, no. 7, pp. 19741980, 2006.

[17] R. M. Gray, "Toeplitz and circulant matrices: a review," Foundations and Trends in Communications and Information Theory, vol. 2, no. 3, pp. 155-239, 2006.

[18] M. Arnout, F. Baudoin, L. Berquez, and D. Payan, "Procédé d'identification de la matrice de transfert d'une cellule de mesure PEA," FR 2981165, 2013.

[19] T. Paulmier, B. Dirassen, D. Payan, and M. Van Eesbeek, "Material charging in space environment: experimental test simulation and induced conductive mechanisms," IEEE Transactions on Dielectrics and Electrical Insulation, vol. 16, no. 3, pp. 682-688, 2009.

[20] M. Arnaout, T. Paulmier, B. Dirassen, and D. Payan, "Noncontact in-situ pulsed electro acoustic method for the analysis of charge transport in irradiated space-used polymers," Journal of Electrostatics, vol. 77, pp. 123-129, 2015.

[21] T. Paulmier, B. Dirassen, M. Arnaout, D. Payan, and N. Balcon, "Electric properties of space used polymers under high energy electron irradiation," in Proceedings of the IEEE International Conference on Solid Dielectrics (ICSD '13), pp. 788-791, Bologna, Italy, June 2013. 

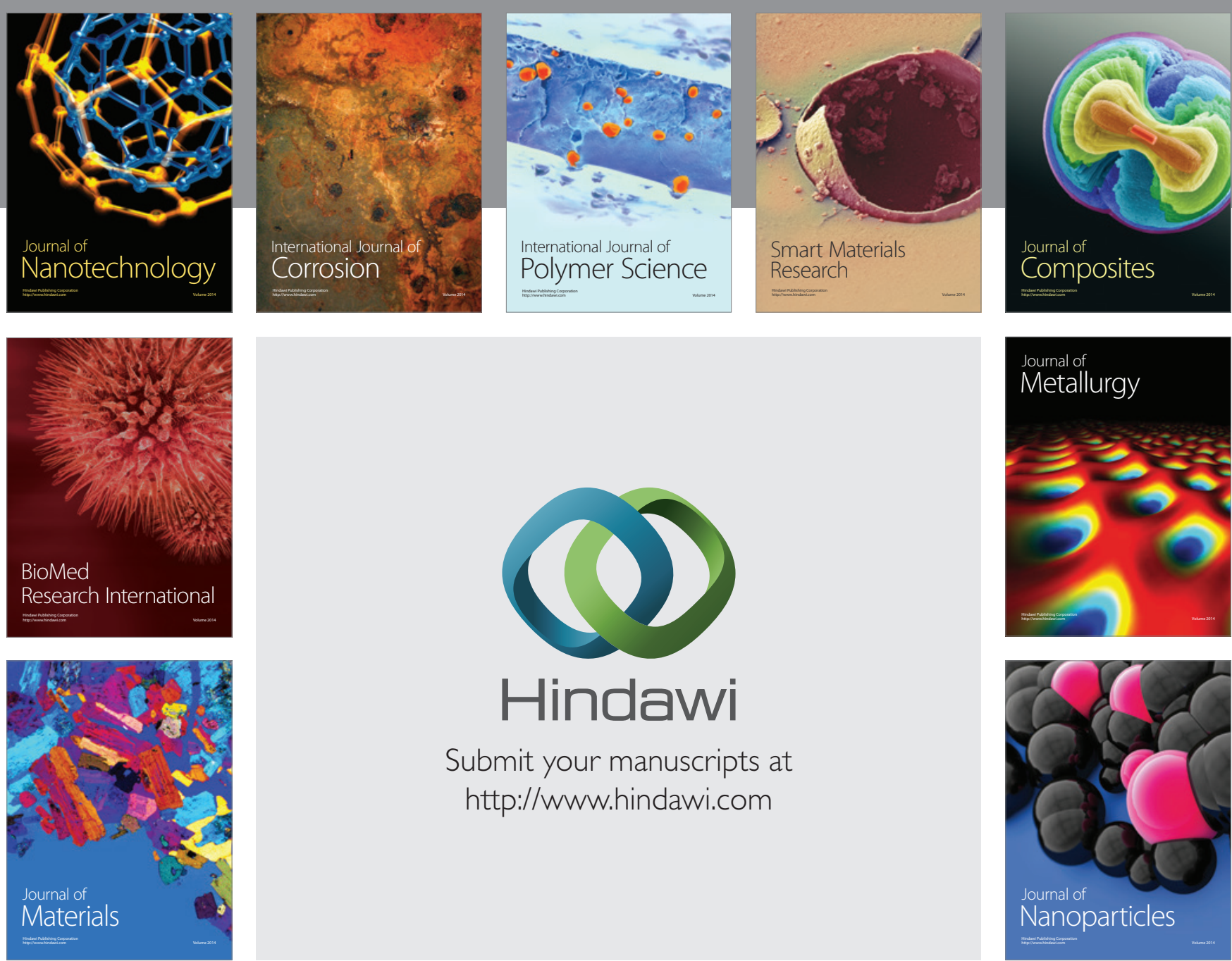

\section{Hindawi}

Submit your manuscripts at

http://www.hindawi.com

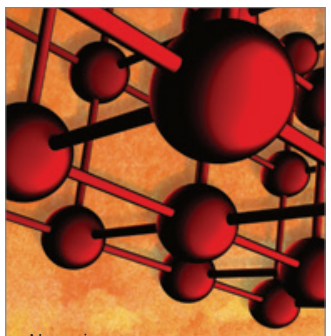

Materials Science and Engineering
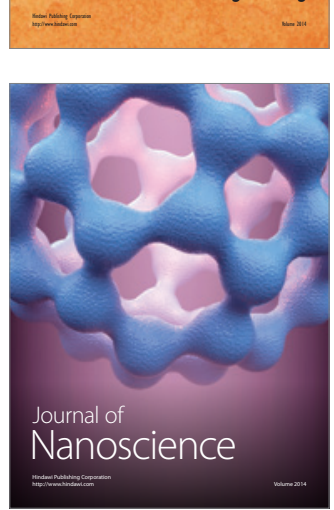
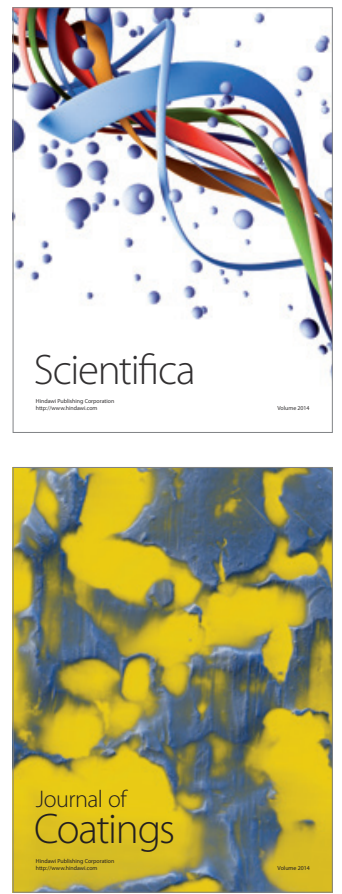
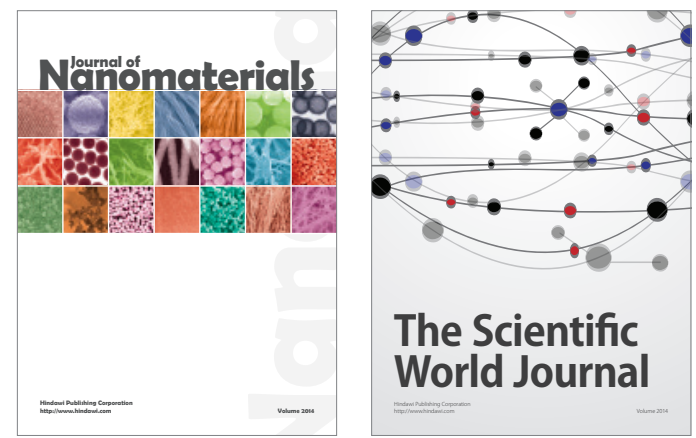

The Scientific World Journal
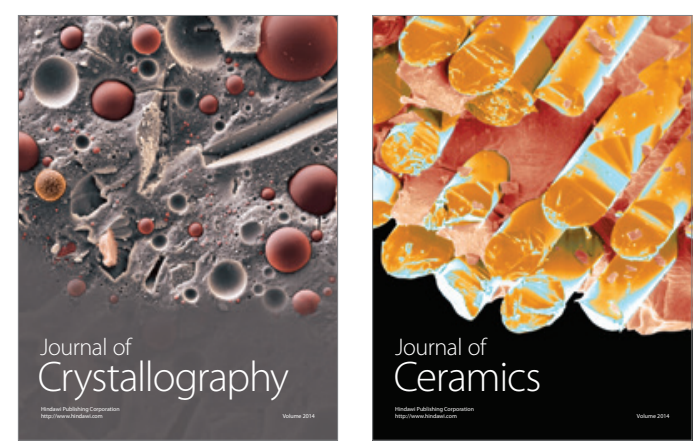
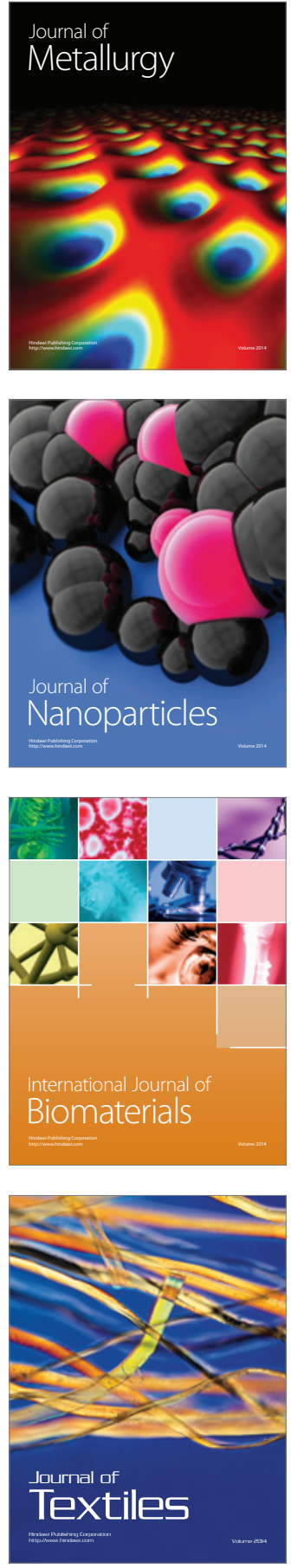